Review Article

\title{
Influence of Antioxidant-Enhanced Polymers in Bitumen Rheology and Bituminous Concrete Mixtures Mechanical Performance
}

\author{
Samer Dessouky, ${ }^{1}$ Mohammad Ilias, ${ }^{2}$ Dae-Wook Park, ${ }^{3}$ and In Tai Kim ${ }^{4}$ \\ ${ }^{1}$ Department of Civil and Environmental Engineering, University of Texas at San Antonio, One UTSA Circle, \\ San Antonio, TX 78249-0668, USA \\ ${ }^{2}$ Fugro Roadware, Inc., 8613 Cross Park Drive, Austin, TX 78754, USA \\ ${ }^{3}$ Department of Civil Engineering, Kunsan National University, 558 Daehak-ro, Kunsan, Chellabuk-do 573-701, Republic of Korea \\ ${ }^{4}$ Department of Transportation Engineering, Myongii University, San 38-2, Namdong, Yongin-si, \\ Gyeonggi-do 449-728, Republic of Korea \\ Correspondence should be addressed to In Tai Kim; kit1998@mju.ac.kr
}

Received 21 August 2015; Accepted 3 November 2015

Academic Editor: Jun Liu

Copyright (C) 2015 Samer Dessouky et al. This is an open access article distributed under the Creative Commons Attribution License, which permits unrestricted use, distribution, and reproduction in any medium, provided the original work is properly cited.

\begin{abstract}
This paper evaluates the effect of polymer enhancement with antioxidant in the rheological properties of bitumen and mechanical properties of bituminous concrete mixture (BCM). In this study, two antioxidant-enhanced polymers were utilized in mitigating bitumen hardening due to aging. The rheological testing consists of temperature sweep using Dynamic Shear Rheometer at various aging conditions. Critical stiffness temperature data from the sweep test suggested that enhanced polymer exhibits less long-term hardening and brittleness compared to standard polymer. The mechanical testing consists of dynamic modulus, indirect tensile, flow number, and beam fatigue tests on BCM exposed to short-term aging. Hamburg wheel tracking test was also performed to assess moisture-damage susceptibility. It is found that the enhanced-polymer BCM exhibited higher modulus, higher tensile strength ratio, improved rutting resistance, lower moisture-damage susceptibility, and slightly increased fatigue life as compared to standard-polymer BCM.
\end{abstract}

\section{Introduction}

Polymers are amongst the most common bitumen modifiers. They are used to improve bitumen thermoplastic characteristics, flexibility under loading, and thermal stability under environmental changes. Their role in bitumen modification depends primarily on their physical properties, content, sources, and chemical compositions [1]. The deterioration of the polymer-modified bitumen (PMB) over time is dependent on the combined effect of bitumen oxidation (aging) and polymer degradation [2]. This occurs during the in-service phases of construction and traffic due to exposure to temperatures, shear forces, and air. The aging changes the molecular structure and degrades the chemical composition of the polymers and bitumen. Aging in bitumen causes hardening due to loss of volatile oil components and rearrangement of bitumen molecules.

Different types of polymers can alter the bitumen properties differently. Styrene-butadiene-styrene (SBS), styrene ethylene-butylene-styrene (SEBS), EVA (ethylene vinyl acetate), and EBA (ethyl butyl acetate) are common polymers used in bitumen modifications. EVA and EBA improved the binder performance at high temperature while SBS and SEBS are effective over a wide range of temperatures [3]. Airey [4] remarked that SBS polymer improves the rheological properties at high temperature and increases elastic properties at low frequency but has insignificant effect at low temperature. Kök and Çolak [5] noted that mixtures with crumb rubber-modified bitumen outperformed the SBS modification. Sengoz and Isikyakar [3] analyzed standard SBS 
polymer at different percentages in bitumen physical properties and mixtures mechanical properties. They found that penetration was decreased, softening point was increased, and temperature susceptibility was decreased with increasing polymer content. Based on the mechanical properties of BMC, they stated that stability and indirect tensile strength will increase when the polymer content does not exceed 5\%.

The effectiveness of the polymer modification tends to diminish as bitumen undergoes aging. When polymers degrade, they experience a change in their physical and chemical properties resulting in loss of their thermoplastic characteristics. This in turn results in decreased PMB resistance to cracking, reduced durability, and shortened service life. Several studies investigated the aging effect on PMB. Wu et al. [6] studied the influence of aging on the evolution of structure, morphology, and rheology of bitumen. $\mathrm{Lu}$ and Isacsson [7] studied the effect of aging on bitumen chemistry and rheology. Durrieu et al. [8] looked into the influence of ultraviolet radiation on bitumen aging. Li et al. [9] remarked that the aging process of polymers involved four stages, namely, initiation, growth, transfer, and termination of free radicals. During aging, free radicals are formed from breakage of polymer chain bonds caused by their exposure to heat or light. These free radicals are ready to oxidize as soon as they come in contact with oxygen forming peroxy radicals (i.e., peroxides). These peroxy radicals further react with polymers to form new free radicals and this cycle repeats itself.

One of the methods used to mitigate aging is the antioxidants ( $\mathrm{AO}$ ) additives. The $\mathrm{AO}$ act in two different ways, either by inhibiting the formation of peroxides or by scavenging the free radical. Li et al. [9] observed that $\mathrm{AO}$ work as scavengers of free radicals facilitating the decomposition of hydroperoxides, which improve the aging resistance. The AO also slow down the age hardening of bitumen resulting in softer behavior at lower and higher temperatures. Hydrated lime [10], Vitamin E, and DLTDP [11] and zinc dialkyldithiophosphate [12] are examples of stand-alone antioxidants that are used to mitigate aging for bitumen. Hindered amine stabilizers and hindered phenolic and sulfur compounds are examples of antioxidants that terminate the chain through reaction with peroxyl radicals. Plancher et al. [10] study the effect of hydrated lime on the hardening of BCM suggesting that the aging index of lime treated mixtures was lower than untreated ones. The aging index was also dependent on the aggregates and bitumen sources used in the experiment. Apeagyei et al. [13] evaluated the effects of $\mathrm{AO}$ on rheological properties of $\mathrm{PMB}$ at different aging levels. They reported that PMB with AO exhibited higher stiffness at higher temperature and lower stiffness at lower temperature as compared to unmodified $\mathrm{PMB}$. The study remarked that mixtures with AO control the reduction in creep compliance due to aging and enhanced the tensile strength as compared to unmodified mixtures. Apeagyei [11] evaluated the age hardening of bitumen blended with numerous AO. Depending on the rheological property, he noted that a combination of DLTDP (dilauryl thiodipropionate) and furfural represented the lowest aging index among all AO-enhanced bitumen materials. The study observed that
TABLE 1: Technical data of the two polymers.

\begin{tabular}{lccc}
\hline Polymer properties & Conventional SBS & SP & CP \\
\hline Toluene viscosity, cP & 2300 & 4000 & 1900 \\
Volatile matter, \% max & 0.40 & 0.75 & 0.50 \\
Total styrene \% & 31.5 & 25 & 32 \\
\hline
\end{tabular}

AO soften the bitumen at lower temperature and stiffen it at higher temperature.

There are numerous studies that address the AO effect in aging retardation for base bitumen, polymers, and PMB [1$3,6,8,12,18]$. The current literature suggests limited studies that investigate the $\mathrm{AO}$ embedded in polymers to enhance $\mathrm{PMB}$ performance. Therefore, this study aims to fill in this gap and investigate the effectiveness of $\mathrm{AO}$-enhanced polymers in mitigating age hardening for $\mathrm{PMB}$ and $\mathrm{BCM}$. The age hardening in the PMB will be quantified using the complex modulus index by comparing the enhanced and control bitumen. The age hardening will be indirectly quantified in the BCM through comparing the performance-related mechanical properties attributed to aging (e.g., dynamic modulus, flow number, moisture damage, and fatigue) for enhanced and control mixes. The uniqueness of these AOenhanced polymers is that they are pretreated with hindered phenols at $3 \%$ by weight of polymers during their production. With the rising cost of crude oil, there is a pressing need to maximize the PMB durability and service life.

\section{Materials}

Two AO-enhanced polymers were used in this study, namely, S-polymer (SP) and C-polymer (CP). The SP is a SBS Block polymer consisting of $25 \%$ styrene content and $17.5 \%$ polystyrene block. The SP is a widely used polymer for improving bitumen stiffness and thermal stability. The CP is a 68/32 SEBS polymer that helps improve ductility. The properties of the polymers are shown in Table 1 . A conventional untreated SBS polymer was used as a base.

Unmodified neat bitumen (PG 64-22) was blended with all polymers. A $3 \%$ polymer content by weight of bitumen was used to enhance stiffness and ductility at high and low temperature, respectively $[14,15]$. The polymers were blended using a high-shear heavy-duty mixer at speed of 1500$2000 \mathrm{rpm}$ for $4-5$ hours at $149^{\circ} \mathrm{C}$. The mixing temperature was identified by the polymer supplier. After the mixing, full dispersion was achieved and no phase separation was noticed [14]. The result of the bitumen-polymer blending was a performance grade (PG) 70-22. Three types of PMB are evaluated in this study: conventional nonenhanced SBS modified bitumen referred to here as PG70 and two AOenhanced PMB referred to as CP and SP. All PMB contain the same polymer content at $3 \%$ by weight of bitumen. Bituminous concrete mixtures (BCM) were molded using the three PMB to evaluate the effectiveness of AO-enhanced polymers in the mechanical properties. The mixture consists of locally sourced fine-grained limestone and 5\% PMB content by weight of aggregates meeting Texas Department of Transportation specifications for dense graded design. All 
TABLE 2: Aggregate gradation and mixture volumetric properties.

\begin{tabular}{|c|c|c|c|c|c|c|c|c|}
\hline Sieve size $(\mathrm{mm})$ & 19 & 12.5 & 9.5 & 4.75 & 2.36 & 0.6 & 0.3 & 0.075 \\
\hline $\begin{array}{l}\text { Passing percent } \\
(\%)\end{array}$ & 100 & 100 & 99.2 & 63.8 & 38.2 & 16.8 & 11.7 & 3.3 \\
\hline $\begin{array}{l}\text { Voids in mineral } \\
\text { aggregate (VMA) }\end{array}$ & \multicolumn{8}{|c|}{15.4} \\
\hline $\begin{array}{l}\text { Bulk specific } \\
\text { gravity at } N_{\text {des }}\end{array}$ & \multicolumn{8}{|c|}{2.366} \\
\hline $\begin{array}{l}\text { Maximum specific } \\
\text { gravity, } G_{\mathrm{mm}}\end{array}$ & \multicolumn{8}{|c|}{2.456} \\
\hline $\begin{array}{l}\text { Effective specific } \\
\text { gravity, } G_{\mathrm{mb}}\end{array}$ & \multicolumn{8}{|c|}{2.658} \\
\hline
\end{tabular}

mixtures were short-term oxidized for four hours in an aircirculating oven at $165^{\circ} \mathrm{C}$ as recommended by the bitumen supplier. The aged mixtures were compacted to achieve target air voids of 7-9\% using Superpave gyratory compactor with volumetric properties as shown in Table 2.

\section{Laboratory Testing}

Aging of bitumen causes distinctive characteristics for BCM such as reduction in fatigue life, decreasing tensile strength and ductility, increasing moisture-damage susceptibility, and increasing rutting and shear resistance. Therefore, the experimental program was chosen to assess these characteristics by testing the aging-related rheological properties of PMB as well as the mechanical properties of BCM. The rheological testing of PMB included temperature sweep using Dynamic Shear Rheometer (DSR) at various aging conditions. The mechanical performance testing included dynamic modulus, indirect tensile, flow number, and four-point beam fatigue tests. Testing was performed using the Universal Testing Machine, a hydraulic-driven load frame system with thermal control capability. Moreover, the Hamburg wheel tracking testing was performed to evaluate the moisture susceptibility using the Asphalt Pavement Analyzer system.

\section{Rheological Analysis of PMB}

Aging affects the rheological properties and temperature susceptibility of bitumen. Mastrofini and Scarsella [2] remarked that aging substantially changes the bitumen properties at high temperature. The reason is that the properties of bitumen are affected by the existence of asphaltenes and maltenes which tend to degrade under aging. In this study, rheological properties were assessed using the temperature sweep testing using DSR on $25 \mathrm{~mm}$ diameter and $1 \mathrm{~mm}$ thick bitumen specimen at temperature range of $20-100^{\circ} \mathrm{C}$ and frequency of $10 \mathrm{rad} / \mathrm{sec}$ at different aging conditions [16]. The test assesses the $\mathrm{PMB}$ viscoelastic behavior at a wide range of in-service temperatures at different aging states. Each specimen was tested at two aging states: rolling thin film oven (RTFO) aged and pressure aging vessel (PAV) aged conditions. The test provides the viscoelastic properties (e.g., complex shear modulus, $\left|G^{*}\right|$, and phase angle, $\delta$ ) evolution with respect to temperature in the form of isochronal plots. The isochronal plots are used to evaluate the effect of temperature on $\left|G^{*}\right|$ and $\delta$ due to aging [4] as shown in Figure 1. As expected, the shear modulus decreases from an elastic-like behavior at the intermediate temperature $\left(20^{\circ} \mathrm{C}\right)$ to a viscous-like behavior at high temperatures. The flattened response at the intermediate range $\left(20-40^{\circ} \mathrm{C}\right)$ of the PAV sample suggests that $\left|G^{*}\right|$ is relatively constant over these temperatures. This flattened range is expanded as the bitumen undergoes aging. It is expected that the polymer network after PAV has been completely aged in which the PMB stiffness becomes less sensitive to temperature changes. This can also be attributed to the formation of a rigid network block created by the action of the polymers [17] at aged condition. Moreover, the extent of hardening is observed as $\left|G^{*}\right|$ increases due to PAV aging compared to RTFO only, particularly at higher temperature range. The influence of the AO-enhanced polymers is apparent in two aspects of the bitumen behavior. The first consists of the higher modulus observed for the SP and CP, particularly at high temperatures. This suggests improving stiffness which is a desirable characteristic for rutting resistance early in the pavement's life. The second consists of slightly softer behavior for the $\mathrm{CP}$ at the intermediate temperature range. This suggests improving ductility, a desirable characteristic for enhancing fatigue resistance of pavement.

The phase angle represents the ratio of dissipated energy to stored energy, ranging from $0^{\circ}$ for elastic to $90^{\circ}$ for viscous materials. Measurements suggested that PMB exhibited increased elastic behavior as temperature decreased and aging level increased. The enhanced PMB, SP and CP, increased the elastic behavior at high temperatures after aging as suggested by the decrease in phase angle. The SP exhibited higher viscous-like behavior at intermediate temperatures after PAV suggesting improved bitumen long-term flexibility and durability.

Figure 2 is referred to as the black diagram defined as the relationship between $\left|G^{*}\right|$ and phase angle excluding the effect of temperature [4]. The figure suggests that, as $\left|G^{*}\right|$ increases, the phase angle decreases. However, a sharp drop in the phase angle is remarked as the modulus exceeds $200 \mathrm{kPa}$ at which PMB behaves as an elastic-like material. Under unaged condition, the enhanced polymers reduce $\left|G^{*}\right|$ and phase angle as compared to the standard polymers. This behavior continues as the PMB undergo RTFO and PAV aging. However, as $\left|G^{*}\right|$ exceeds $200 \mathrm{kPa}$, the black diagram depicts crossover in which the modulus of the enhanced $\mathrm{PMB}$ exceeds the control one. Moreover, long-term aging has tendency to eliminate the effect of enhanced polymer in the rheological testing, as shown in Figure 2(c). The black diagram presented insignificant difference between $\mathrm{CP}$ and $\mathrm{SP}$. The diagram suggests that the AO-enhanced polymers increase the modulus of the PMB as compared to standard polymer under low shear conditions and inversely reduce the stiffness under high-shear conditions.

\section{Aging of PMB}

Aging of bitumen is a combination of two processes, irreversible due to chemical reaction and reversible due 

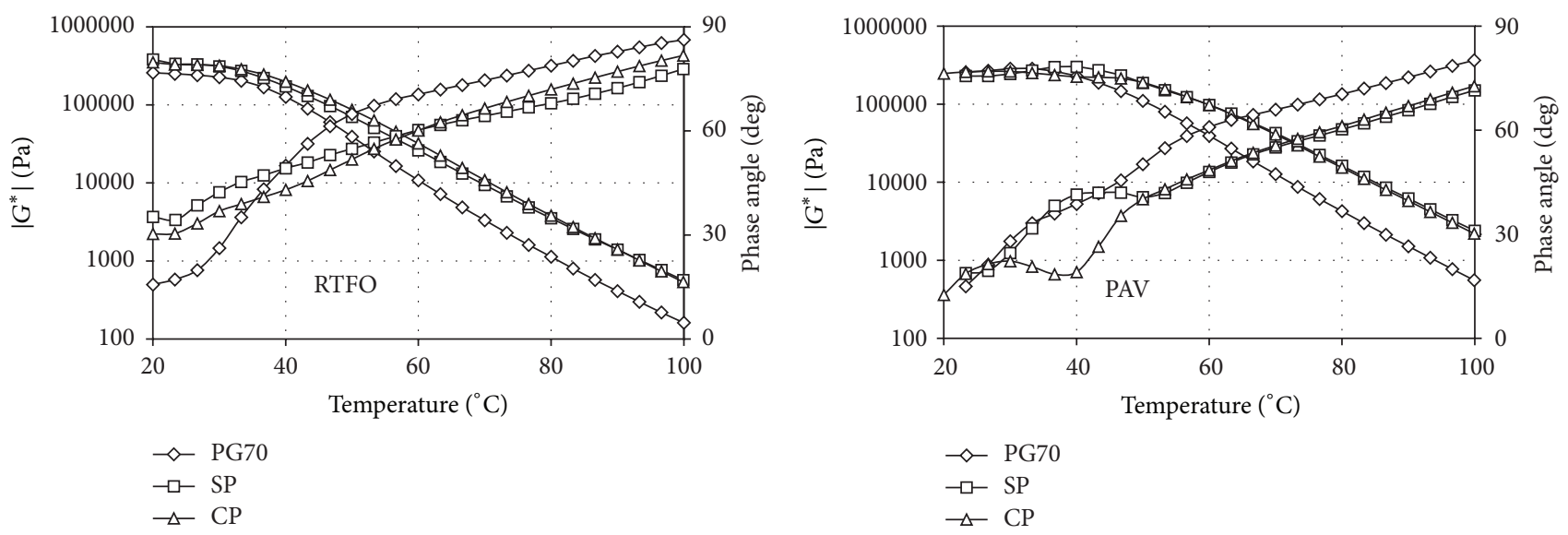

FIGURE 1: Isochronal plots for RTFO and PAV aged PMB.
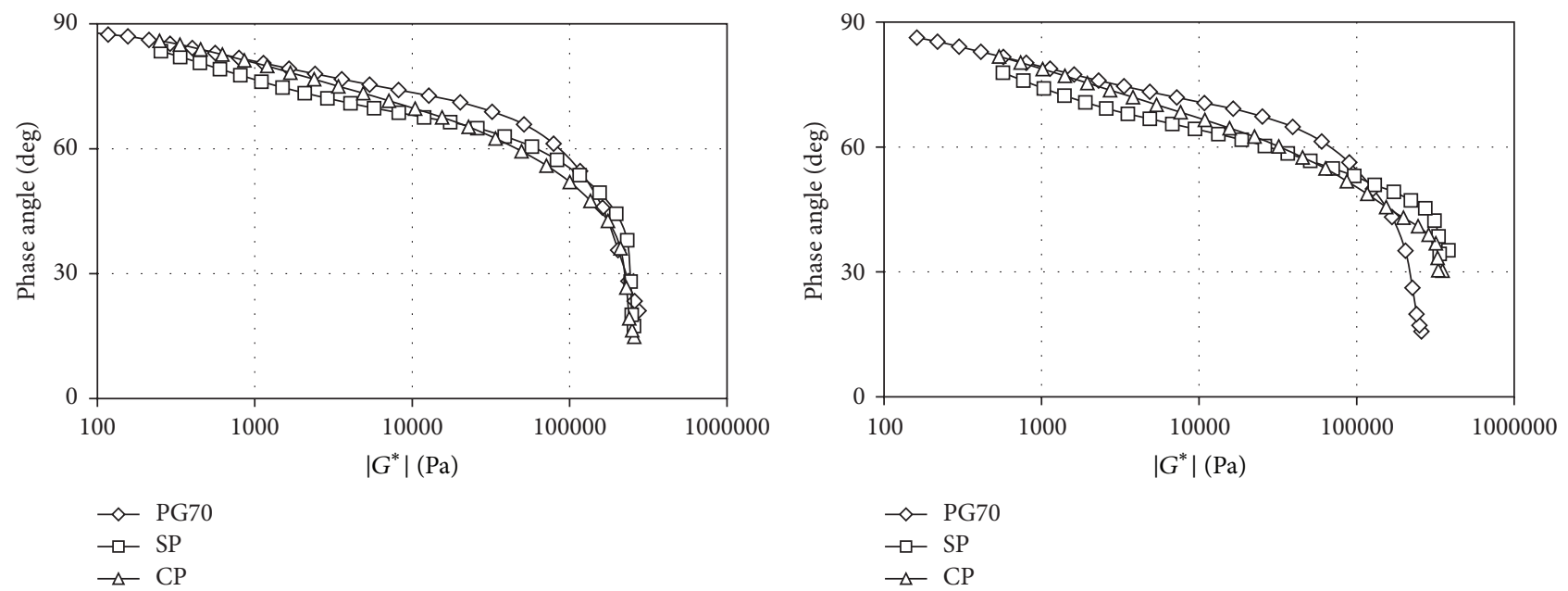

(a) Unaged

(b) RTFO

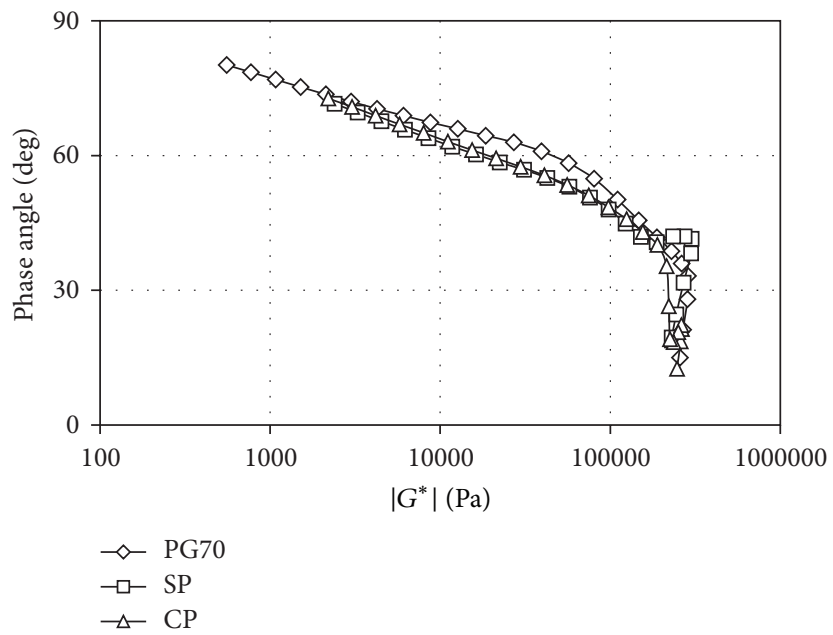

(c) PAV

FIgURE 2: Black diagram for (a) unaged, (b) RTFO, and (c) PAV aged PMB. 

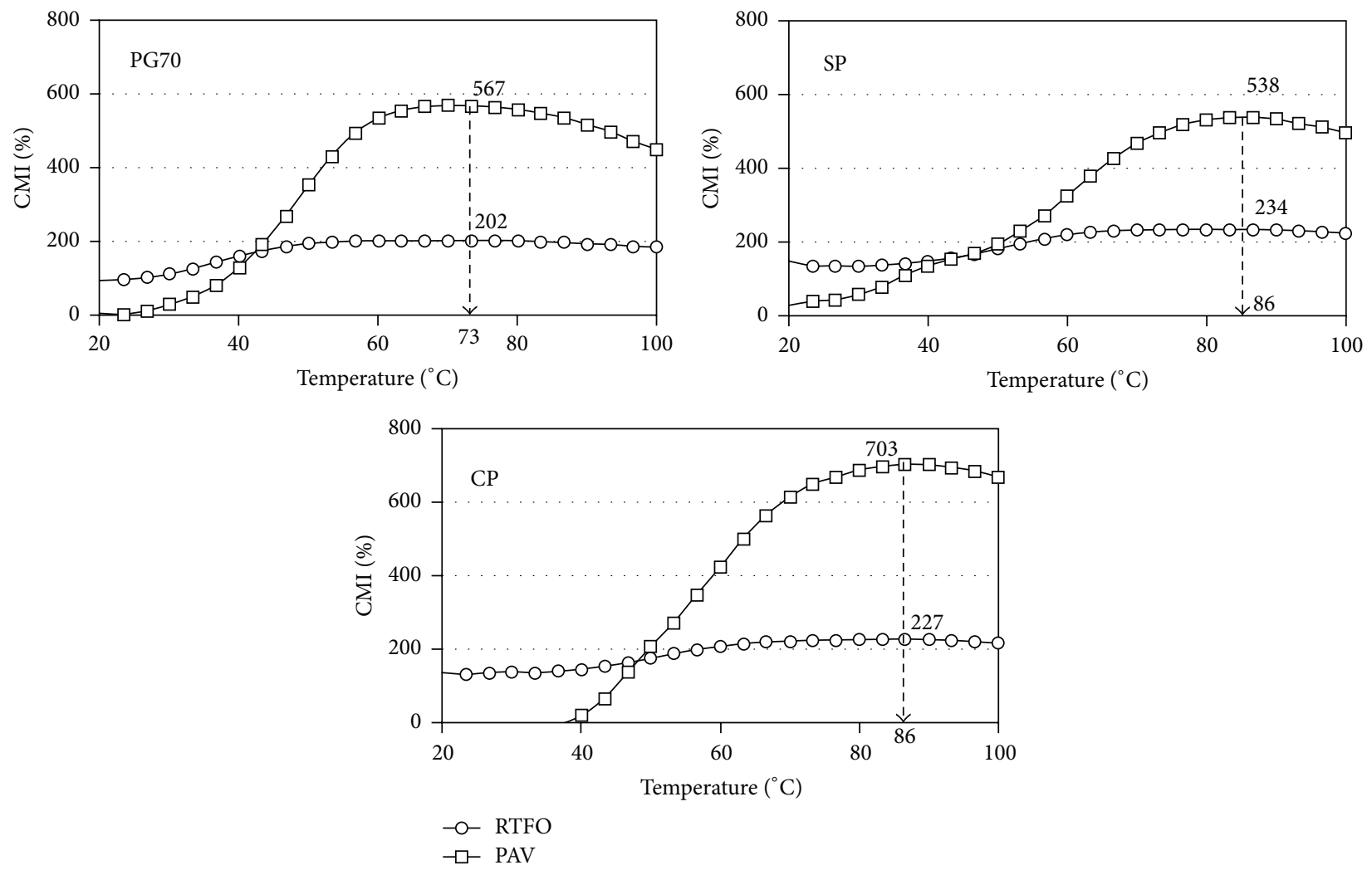

FIGURE 3: CMI showing the critical stiffness temperatures of bitumen.

to physical changes resulting in hardening. Ouyang et al. [12] studied the aging resistance of PMB enhanced with $\mathrm{AO}$ additives (e.g., zinc dialkyldithiophosphate and dibutyl dithiocarbamate) using Fourier Transform Infrared (FTIR) spectroscopy. They remarked that AO worked as aging resistant agents by producing carbonyl in the modified bitumen. Cortizo et al. [18] performed rheological and infrared spectroscopy testing on $\mathrm{PMB}$ in different aging states and noted that the hardening of PMB depends on structural characteristics of the added polymers. In addition, during thermal degradation of PMB, higher molecular size was formed due to free radical reaction and due to the existence of the polar compounds. They found that the aging index of PAV for PMB is more than that of RTFO. Lu and Isacsson [1] remarked that the property of PMB depends not only on the properties of polymers but also on the source and properties of base bitumen. In their study, they used different polymers (SBS, SEBS, EVA, and EBA) and three types of base bitumen. Based on the rheological properties of base bitumen and PMB, they found that SBS and SEBS showed better performance than EVA and EBA. EVA and EBA improved PMB performance at high temperature while SBS and SEBS improved performance over a wide range of temperatures. For instance, the PMB creep stiffness was reduced more in the case of SBS and SEBS than that for EVA and EBA at $-35^{\circ} \mathrm{C}$. Li et al. [9] attempted to improve the thermal aging resistance of SBS polymer by using AO. They found that AO improved resistance to thermal hardening based on dynamic mechanical analysis and FTIR spectroscopy testing.
In this study, the hardening effect of the AO-enhanced PMB was evaluated by determining the critical stiffness temperature using unaged and aged measurements [14]. Critical stiffness temperature is referred to as the temperature corresponding to the peak stiffness of bitumen due to aging. It also represents the highest resistance to permanent deformation under oxidative conditions. To determine the peak stiffness, the complex modulus indices (CMI) were determined based on $\left|G^{*}\right|$ at oxidative conditions expressed as follows:

$$
\begin{aligned}
\mathrm{CMI}_{(\mathrm{RTFO})} \% & =100 \times\left[\frac{\left|G_{(\mathrm{RTFO})}^{*}\right|}{\left|G_{(\text {Unaged })}^{*}\right|}\right] \\
\mathrm{CMI}_{(\mathrm{PAV})} \% & =100 \times\left[\frac{\left(\left|G_{(\mathrm{PAV})}^{*}\right|-\left|G_{(\mathrm{RTFO})}^{*}\right|\right)}{\left|G_{(\text {Unaged })}^{*}\right|}\right] .
\end{aligned}
$$

Equations (1) and (2) represent the bitumen hardening due to aging by RTFO and PAV independently. For instance, the hardening effect of RTFO is subtracted in (2) to isolate the aging effect of PAV. The CMI provides a quantifiable measure of bitumen thermal stability. This index associates the change in aged with unaged properties as temperature changes [15]. Bitumen with high thermal sensitivity is indicated by high CMI (i.e., greater than 100\%), and vice versa. Representation of the CMI as a function of temperature is shown in Figure 3. The figure depicts that the critical temperature coincides with the RTFO and PAV aging. The figure also depicts that the 


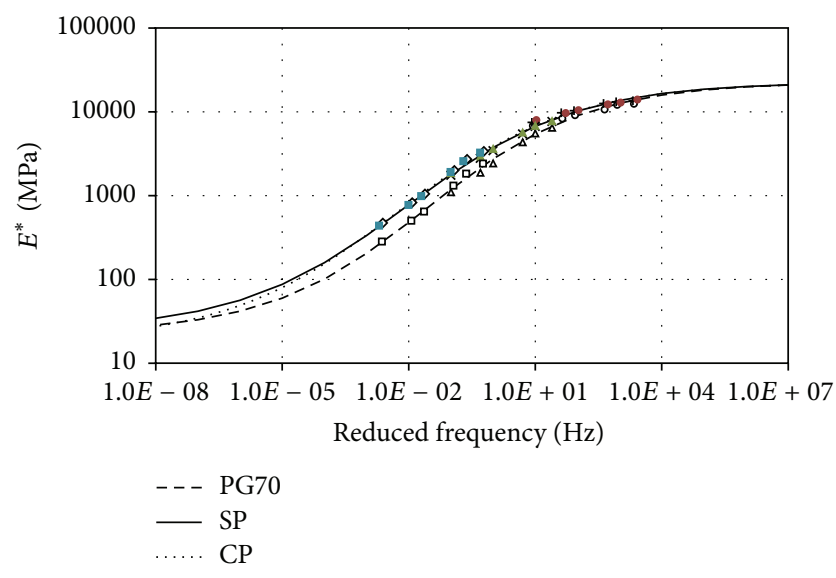

FIgURE 4: $E^{*}$ master curve at reference temperature of $21^{\circ} \mathrm{C}$.

critical temperature increases significantly when an enhanced polymer is used. The critical temperature is 73,86 , and $86^{\circ} \mathrm{C}$ for PG70, SP, and CP, respectively. After RTFO, SP and CP marginally increased CMI at all testing temperatures and particularly by 15.8 and $12.3 \%$ at the critical temperature, respectively. It is suggested that the enhanced polymer tends to exhibit more hardening at elevated temperature which is preferable to improve rutting resistance in early life of $\mathrm{BCM}$. Using the difference in CMI at the corresponding temperatures for each $\mathrm{PMB}$, it was determined that $\mathrm{CP}$ and SP have increased short-term hardening at high temperature range $\left(64-86^{\circ} \mathrm{C}\right)$ by 11 and $17 \%$, respectively. After PAV, CP has significantly reduced the long-term hardening (improved fatigue cracking resistance) at intermediate temperature range $\left(20-36^{\circ} \mathrm{C}\right)$. SP has reduced the long-term hardening at high temperature range $\left(64-86^{\circ} \mathrm{C}\right)$ by $15 \%$. At the critical temperatures in particular, the $\mathrm{CMI}$ is $567 \%, 538 \%$, and $703 \%$ for PG70, SP, and CP, respectively.

\section{Mechanical Testing Analysis of Mixture}

Dynamic modulus testing was conducted according to AASHTO TP 62-07 [19] at temperatures of 4, 21, and $37^{\circ} \mathrm{C}$ and frequencies of $0.1,0.5,1.0,5,10$, and $25 \mathrm{~Hz}$. The significance of this test is to determine $\left|E^{*}\right|$, a viscoelastic material property of BCM that reflects its stiffness at a wide range of temperatures and/or frequencies in the form of a master curve. Compacted BCM of $100 \mathrm{~mm}$ in diameter and $150 \mathrm{~mm}$ in height at air voids of 6-8\% were used to establish the master curve at a reference temperature of $21^{\circ} \mathrm{C}$ as shown in Figure 4. Using the experimental data and the extrapolation technique by Christensen et al. [20], one can extend the master curve to a larger frequency range. Equation (3) was used to form the master curve:

$$
\begin{aligned}
& \log \left(E^{*}\right) \\
& \quad=\delta+\frac{(\operatorname{Max}-\delta)}{1+e^{\beta+\gamma\left\{\log (t)-\left(\Delta E_{a} / 19.14714\right)[(1 / T)-(1 / 295.25)]\right\}},},
\end{aligned}
$$

where $E^{*}$ is the dynamic modulus, $t$ is the loading time, $T$ is the temperature $\left({ }^{\circ} \mathrm{K}\right)$, Max is the limiting maximum modulus,
TABLE 3: Results of IDT testing.

\begin{tabular}{lccc}
\hline Properties & PG70 & SP & CP \\
\hline Dry tensile strength $(\mathrm{kPa})$ & $620 \pm 40$ & $590 \pm 18$ & $592 \pm 80$ \\
Wet tensile strength $(\mathrm{kPa})$ & $309 \pm 19$ & $354 \pm 30$ & $364 \pm 21$ \\
Tensile strength ratio $(\%)$ & 50.0 & 60.0 & 61.5 \\
\hline
\end{tabular}

and $\beta, \delta, \gamma$, and $\Delta E_{a}$ are fitting parameters from experimental data.

The three mixes exhibit a similar glassy modulus plateau of $21,000 \mathrm{MPa}$ at high loading frequencies. It is suggested that the effect of enhanced polymer in BCM modulus is irrelevant at high frequency but has a distinct effect as frequency decreases. For instance, at low frequency, the enhanced SP mixture exhibited a $20 \%$ higher modulus compared to other mixtures. In the intermediate frequency range (1$100 \mathrm{~Hz}$ ), a potential condition for permanent deformation, the enhanced SP and CP mixtures exhibit higher $\left|E^{*}\right|$ compared to the control mixture. For example, at frequency of $1.6 \mathrm{~Hz}$, corresponding to $0.1 \mathrm{sec}$ loading time [21], $\left|E^{*}\right|$ for PG70, SP, and CP are $2.74 E+03,3.75 E+03$, and $3.83 E+03$, respectively.

Indirect tensile (IDT) testing was performed to evaluate the effect of enhanced polymer in the tensile strength of BCM after freeze/thaw conditioning. Specimens with $100 \mathrm{~mm}$ diameter and $63.5 \mathrm{~mm}$ thickness following AASHTO T 283 [22] were used. Six replicates were molded for control and enhanced BCM, with three tested after dry conditioning and three after wet conditioning. Freeze/thaw conditioning of $\mathrm{BCM}$ specimens was performed at $-18^{\circ} \mathrm{C}$ for 16 hours followed by water submerging at $60^{\circ} \mathrm{C}$ for $24 \mathrm{hr}$ and submerging at $25^{\circ} \mathrm{C}$ for $2 \mathrm{hr}$. The IDT testing was performed by applying a monotonic vertical load along the diametral direction of the specimen until failure. The IDT testing results are summarized in terms of the average and standard deviation of dry and wet tensile strength data (Table 3). The coefficient of variation for each mixture is less than $15 \%$, which is an acceptable value considering the heterogeneity of the mixtures coupled with the uncontrolled splitting initiation and evolution in the IDT. It is also noticed that the tensile strength ratio is greatly below the standard threshold of $80 \%$ [22]. The intention in this test is to compare the IDT results and not to compare the mixes against specification criteria.

The IDT results suggest that the dry tensile strength of the control mixtures is higher by $5 \%$ than enhanced-polymer mixtures. On the contrary, the enhanced-polymer mixtures exhibit higher wet tensile strength by an average of $16 \%$. The tensile strength ratio of wet to dry specimens suggests that the freeze/thaw conditioning reduced the strength by $50 \%$ for the standard-polymer mixtures and $40 \%$ for the enhanced-polymer mixtures. These results suggest that the $\mathrm{AO}$ enhancement improved bitumen-aggregate bonding and reduced moisture-damage susceptibility. This supports the rationale that $\mathrm{AO}$ sustain polymer ductility and mitigate hardening and aging. It is worth mentioning that none of the mixtures satisfied the minimum tensile strength ratio value of $80 \%$ as recommended by AASHTO T 283 [22]. 


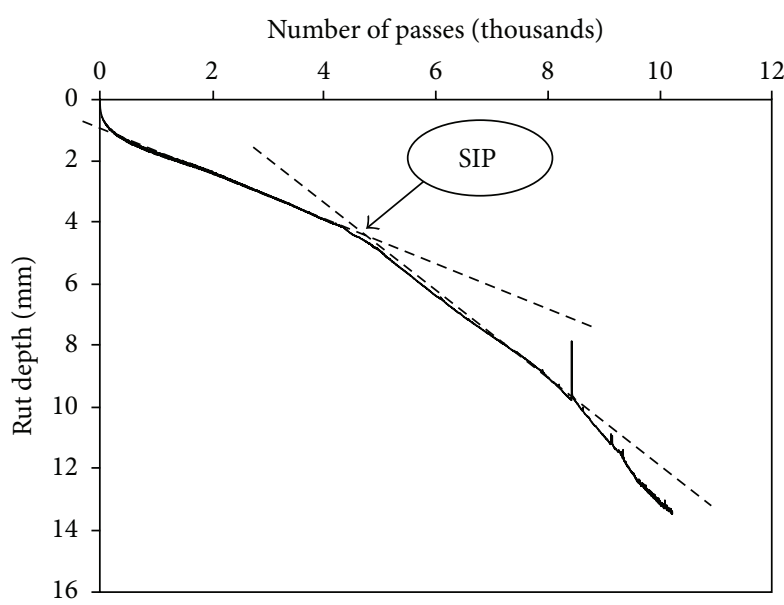

FIGURE 5: The rutting evolution for SP mixture using HWTT.

The Hamburg Wheel Tracking Tester (HWTT) was utilized to evaluate mixture susceptibility to moisture damage due to the lack of insufficient bitumen coating, structural weakness of aggregates, and weak bonding at bitumenaggregate interface. This test was performed on two compacted specimens with $150 \mathrm{~mm}$ diameter and $62 \mathrm{~mm}$ thickness for each polymer type [23]. The testing was operated by applying a steel wheel carrying $703 \mathrm{~N}$ load, rolling over the mixtures at speed of $0.35 \mathrm{~m} / \mathrm{s}$, rate of 50 passes per minute, and temperature of $50^{\circ} \mathrm{C}$. As the wheels roll over the submerged specimens, a combined effect of vertical stresses and moisture infiltration tends to break the bitumenaggregate bonding and induce rutting. Testing was terminated at a maximum rut depth of $12.5 \mathrm{~mm}$ or 20,000 passes whichever occurs first. Figure 5 shows an example of the rut depth evolution with number of passes for the SP mixture. The rutting rate, defined as the slope of the rut depth versus number of passes, increases rapidly as the specimen approaches the failure criteria. The increase in the rate is because the mixtures undergo accumulated phases of stripping and moisture damage. The point (number of passes), where the rutting rate changes, is referred to as a stripping inflection point (SIP). Low SIP is associated with mixtures with high moisture-damage susceptibility and vice versa. More information on SIP can be found elsewhere [24].

The HWTT results in Table 4 remarked that BCM with enhanced polymer are less moisture-damage susceptible compared to the one with control polymer. SP and CP exhibited less rutting depth, higher number of loading passes to failure, higher SIP, and overall less rutting rate. SP, in particular, expressed the best performance among all mixtures, supporting the effectiveness of the $\mathrm{AO}$ role in mitigating polymer and bitumen aging.

To evaluate the rutting resistance of the BCM, the flow number (FN) test was employed. The FN is determined as the number of load cycles corresponding to the minimum rate of axial strain deformation for mixture under uniaxial stress conditions [25]. Mixtures with higher FN are associated with higher rutting resistance and vice versa. Cylindrical specimens similar to the dynamic modulus test were subjected to
TABLE 4: Hamburg wheel tracking testing results.

\begin{tabular}{lccc}
\hline Parameters & PG70 & SP & CP \\
\hline $\begin{array}{l}\text { Max rut } \\
\text { depth }\end{array}$ & $13.6 \pm 0.2$ & $12.9 \pm 0.8$ & $13.2 \pm 0.9$ \\
$\begin{array}{l}\text { Number of } \\
\text { passes }\end{array}$ & $6,719 \pm 3,208$ & $10,200 \pm 31$ & $9,271 \pm 1,415$ \\
$\begin{array}{l}\text { Rutting rate } \\
\text { (mm/passes) }\end{array}$ & $0.002 \pm .01$ & $0.0012 \pm .0001$ & $0.0014 \pm .001$ \\
SIP & $3,525 \pm 1,237$ & $6,225 \pm 106$ & $4,800 \pm 1,980$ \\
\hline
\end{tabular}

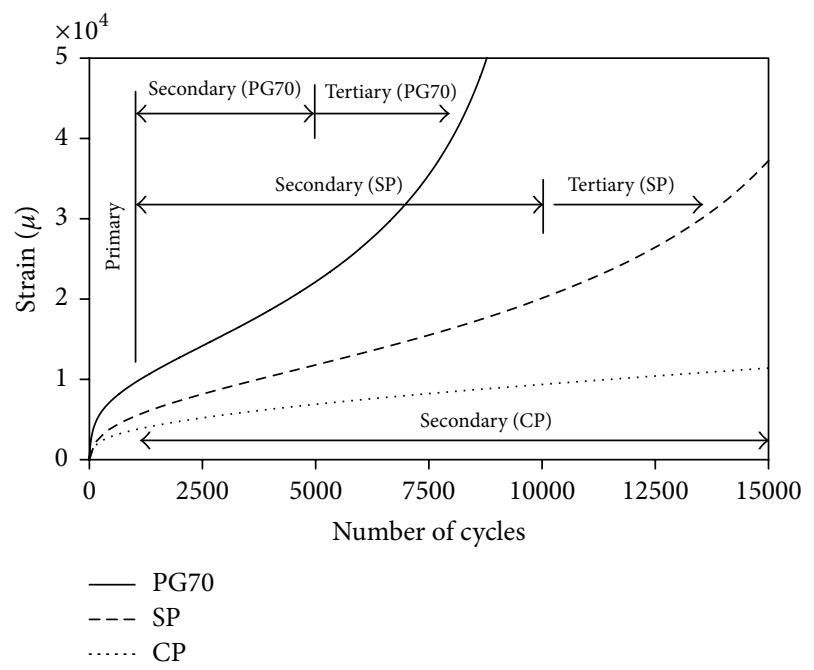

FIGURE 6: Uniaxial strain measurements of FN test.

repeated haversine axial cycles with $0.1 \mathrm{sec}$ loading and $0.9 \mathrm{sec}$ rest period [26]. The test was performed under unconfined conditions for two replicates at $54^{\circ} \mathrm{C}$ and deviatoric stress of $207 \mathrm{kPa}$. Failure criteria were identified by axial strain of 50,000 microstrains or number of cycles of 15,000, whichever occurs first.

During the FN test, the mixture undergoes three stages of creep strain deformation, namely, primary, steady state (secondary), and tertiary deformation [25]. The strain evolution of the BCM is represented in Figure 6. Results showed that control BCM reached tertiary flow earlier compared to the enhanced BCM. The tertiary flow approximately initiated at 5,000, 10,000, and $>15,000$ cycles for PG70, SP, and CP, respectively. On the other hand, accumulated strain in $\mathrm{CP}$ mixture was the lowest among all mixtures without initiation of tertiary creep deformation.

Table 5 suggests that enhanced-polymer BCM have significantly higher FN as compared to the control. The FN increases 3 and 4 times when SP and CP enhanced polymers were utilized, respectively. Results suggest that AO enhancement sustains polymer physical characteristics resulting in improving BCM rutting resistance as compared to standard polymers. These results are in agreement with $\left|E^{*}\right|$ properties in Figure 4 in which the control BCM induced the least modulus among all mixtures.

To assess the BCM fatigue characteristics, the four-point beam fatigue tester was utilized. Repeated bending load was 
TABLE 5: Flow number test data.

\begin{tabular}{lccc}
\hline Parameters & PG70 & SP & CP \\
\hline $\begin{array}{l}\text { Flow } \\
\text { number (FN) }\end{array}$ & $\mathbf{1 5 8 5} \pm \mathbf{5 2 7}$ & $\mathbf{4 5 9 7} \pm \mathbf{7 6 3}$ & $\mathbf{6 4 3 7} \pm \mathbf{1 2 2}$ \\
$\begin{array}{l}\text { Rate of strain } \\
\text { at FN }\end{array}$ & $2.0 \pm 0.6$ & $0.38 \pm 0.18$ & $0.38 \pm 0.18$ \\
$\begin{array}{l}\text { Microstrain } \\
\text { at FN }\end{array}$ & $13000 \pm 1058$ & $11700 \pm 200$ & $10461 \pm 2480$ \\
$\begin{array}{l}\text { Terminating } \\
\text { number of } \\
\text { cycles }\end{array}$ & $5792 \pm 2600$ & 15000 & 15000 \\
$\begin{array}{l}\text { Maximum } \\
\text { strain } \\
\text { (micron) }\end{array}$ & 50000 & $43540 \pm 9149$ & $17617 \pm 6490$ \\
\hline
\end{tabular}

TABLE 6: Beam fatigue test data.

\begin{tabular}{lccc}
\hline Parameters & PG70 & SP & CP \\
\hline Average $N_{f}(1000$ cycles $)$ & 884 & 1,000 & 898 \\
Std. deviation $(* 1000)$ & 102 & 0 & 177 \\
COV $(\%)$ & 11.5 & 0 & 20 \\
\hline
\end{tabular}

applied on BCM beams to determine flexural stiffness. The beam stiffness is determined by the ratio of the maximum tensile stress and the maximum tensile strain. As the beam undergoes repeated flexural loading, the mixture stiffness drops. Terminating flexural stiffness is half the initial beam stiffness. The number of cycles corresponding to the terminating stiffness is referred to as the fatigue life $\left(N_{f}\right)$. The strain-controlled test was performed using four point loading pins $119 \mathrm{~mm}$ apart over $380 \mathrm{~mm}$ length, $50 \mathrm{~mm}$ thickness, and $63 \mathrm{~mm}$ width BCM beams. As suggested by AASHTO $T 321$ [27], the strain level should be between 250 and 750 microstrains; therefore, testing was conducted at 300 microstrains, frequency of $10 \mathrm{~Hz}$, and temperature of $21^{\circ} \mathrm{C}$. Six replicate beams were tested to establish the strain-fatigue life relationship. Mixtures were manually compacted in slabs using an in-house steel mold to achieve $7-9 \%$ air voids.

Table 6 presented the average and standard deviation of fatigue life for each mixture. As shown in the table, the beam fatigue testing suggests that the mixes exhibit slight improvement in the fatigue life with the $\mathrm{AO}$ additives. The table suggested that the fatigue life improved by 13 and $2 \%$ with SP and CP enhanced mixtures, respectively. The variability in the testing results was less than $20 \%$ which is acceptable for these kinds of tests that are normally known for their high variability.

\section{Conclusion}

An experimental program was established to investigate the influence of $\mathrm{AO}$-enhanced polymers on mitigating age hardening of bitumen and improving BCM mechanical properties. The AO-enhanced polymer effect was evident in the rheological testing of the PMB. The enhancement increased shear stiffness and improved the elasticity of short-term aged $\mathrm{PMB}$ at high in-service temperatures. The $\mathrm{CP}$ enhancement has shown improvement in the ductility of the long-term aged $\mathrm{PMB}$ at intermediate temperatures.

The performance of the AO-enhanced polymer appears to improve BCM stiffness and increase fatigue life. The stiffness increase of bitumen due to enhanced-polymer modification was reflected in increasing dynamic modulus and rutting resistance. The study also suggested that the AO-enhanced polymers improved bitumen-aggregate bonding and reduced moisture-damage susceptibility and stripping as evident in the HWTT and IDT results. The AO-enhanced polymers have also improved BCM ductility and slightly increased fatigue life in the beam flexural testing.

Further study with different bitumen and aggregate sources is highly recommended. Expanding the testing program to include more performance-based mechanical testing is essential to better understand the mechanism of $\mathrm{AO}$ enhancement in mixture behavior.

\section{Conflict of Interests}

The authors declare that there is no conflict of interests regarding the publication of this paper.

\section{Acknowledgments}

The authors would like to thank Valero Energy Corporation for providing the bitumen and Dynasol for providing the polymers.

\section{References}

[1] X. Lu and U. Isacsson, "Effect of ageing on bitumen chemistry and rheology," Construction and Building Materials, vol. 16, no. 1, pp. 15-22, 2002.

[2] D. Mastrofini and M. Scarsella, "The application of rheology to the evaluation of bitumen ageing," Fuel, vol. 79, no. 9, pp. 10051015, 2000.

[3] B. Sengoz and G. Isikyakar, "Analysis of styrene-butadienestyrene polymer modified bitumen using fluorescent microscopy and conventional test methods," Journal of Hazardous Materials, vol. 150, no. 2, pp. 424-432, 2008.

[4] G. D. Airey, "Rheological properties of styrene butadiene styrene polymer modified road bitumens," Fuel, vol. 82, no. 14, pp. 1709-1719, 2003.

[5] B. V. Kök and H. Çolak, "Laboratory comparison of the crumbrubber and SBS modified bitumen and hot mix asphalt," Construction and Building Materials, vol. 25, no. 8, pp. 3204-3212, 2011.

[6] S.-P. Wu, L. Pang, L.-T. Mo, Y.-C. Chen, and G.-J. Zhu, "Influence of aging on the evolution of structure, morphology and rheology of base and SBS modified bitumen," Construction and Building Materials, vol. 23, no. 2, pp. 1005-1010, 2009.

[7] X. Lu and U. Isacsson, "Modification of road bitumens with thermoplastic polymers," Polymer Testing, vol. 20, no. 1, pp. 77$86,2000$.

[8] F. Durrieu, F. Farcas, and V. Mouillet, "The influence of UV aging of a Styrene/Butadiene/Styrene modified bitumen: comparison between laboratory and on site aging," Fuel, vol. 86, no. 10-11, pp. 1446-1451, 2007. 
[9] Y. Li, L. Li, Y. Zhang, S. Zhao, L. Xie, and S. Yao, “The influence of UV aging of a Styrene/Butadiene/Styrene modified bitumen: comparison between laboratory and on site aging," Journal of Applied Polymer Science, vol. 116, no. 2, pp. 754-761, 2010.

[10] H. Plancher, E. L. Green, and J. C. Petersen, "Reduction of oxidative hardening of asphalts by treatment with hydrated lime-a mechanistic study," Proceedings of the Association of Asphalt Paving Technologists, vol. 45, pp. 1-24, 1976.

[11] A. K. Apeagyei, "Laboratory evaluation of antioxidants for asphalt binders," Construction and Building Materials, vol. 25, no. 1, pp. 47-53, 2011.

[12] C. Ouyang, S. Wang, Y. Zhang, and Y. Zhang, "Improving the aging resistance of styrene-butadiene-styrene tri-block copolymer modified asphalt by addition of antioxidants," Polymer Degradation and Stability, vol. 91, no. 4, pp. 795-804, 2006.

[13] A. K. Apeagyei, W. Buttlar, and B. J. Dempsey, "Investigation of cracking behavior of antioxidant-modified asphalt mixtures," Journal of the Association of Asphalt Paving Technologists, vol. 77, pp. 517-548, 2008.

[14] S. Dessouky, C. Reyes, M. Ilias, D. Contreras, and A. T. Papagiannakis, "Effect of pre-heating duration and temperature conditioning on the rheological properties of bitumen," Construction and Building Materials, vol. 25, no. 6, pp. 2785-2792, 2011.

[15] S. Dessouky, D. Contreras, J. Sanchez, A. T. Papagiannakis, and A. Abbas, "Influence of hindered phenol additives on the rheology of aged polymer-modified bitumen," Construction and Building Materials, vol. 38, pp. 214-223, 2013.

[16] AASHTO T 315, "Determining the Rheological Properties of Asphalt Binder Using a Dynamic Shear Rheometer (DSR)," Washington, DC, USA.

[17] S.-P. Wu, L. Pang, L.-T. Mo, Y.-C. Chen, and G.-J. Zhu, "Influence of aging on the evolution of structure, morphology and rheology of base and SBS modified bitumen," Construction and Building Materials, vol. 23, no. 2, pp. 1005-1010, 2009.

[18] M. S. Cortizo, D. O. Larsen, H. Bianchetto, and J. L. Alessandrini, "Effect of the thermal degradation of SBS copolymers during the ageing of modified asphalts," Polymer Degradation and Stability, vol. 86, no. 2, pp. 275-282, 2004.

[19] AASHTO, "Determining dynamic modulus of hot mix asphalt (HMA)," AASHTO TP 62-07, AASHTO, Washington, DC, USA, 2007.

[20] D. W. Christensen, T. Pellinen, and R. F. Bonaquist, "Hirsch model for estimating the modulus of asphalt concrete," Journal of the Association of Asphalt Paving Technologists, vol. 72, pp. 97-121, 2003

[21] I. L. Al-Qadi, M. Elseifi, P. Yoo et al., "Accuracy of current complex modulus selection procedure from vehicular load pulse in NCHRP 1-37A mechanistic-empirical pavement design guide," Transportation Research Board, vol. 2087, pp. 81-90, 2008.

[22] AASHTO T 283, Resistance of Compacted Hot Mix Asphalt (HMA) to Moisture-Induced Damage, American Association of State Highway and Transportation Officials (AASHTO), Washington, DC, USA, 2010.

[23] AASHTO T 324, Hamburg Wheel-Track Testing of compacted Hot Mix Asphalt (HMA), American Association of State Highway and Transportation Officials (AASHTO), Washington, DC, USA, 2013.

[24] T. Aschenbrener and G. Currier, "Influence of testing variables on the results from the Hamburg wheel tracking device," Tech.
Rep. CDOT-DTD-R-93-22, Colorado Department of Transportation, Denver, Colo, USA, 1993.

[25] R. N. Dongré, J. A. D’Angelo, and A. Copeland, "Refinement of flow number as determined by asphalt mixture performance tester: use in routine control-quality assurance practice," Bituminous Materials and Mixtures, vol. 2, pp. 127-136, 2009.

[26] AASHTO, "Standard method of test for determining the dynamic modulus and flow number for Hot Mix Asphalt (HMA) using the Asphalt Mixture Performance Tester (AMPT)," AASHTO TP 79-09, AASHTO, Washington, DC, USA, 2009.

[27] AASHTO, "Determining the fatigue life of compacted hot mix asphalt subjected to repeated flexural bending," AASHTO T 321, American Association of State Highway and Transportation Officials, Washington, DC, USA, 2011. 

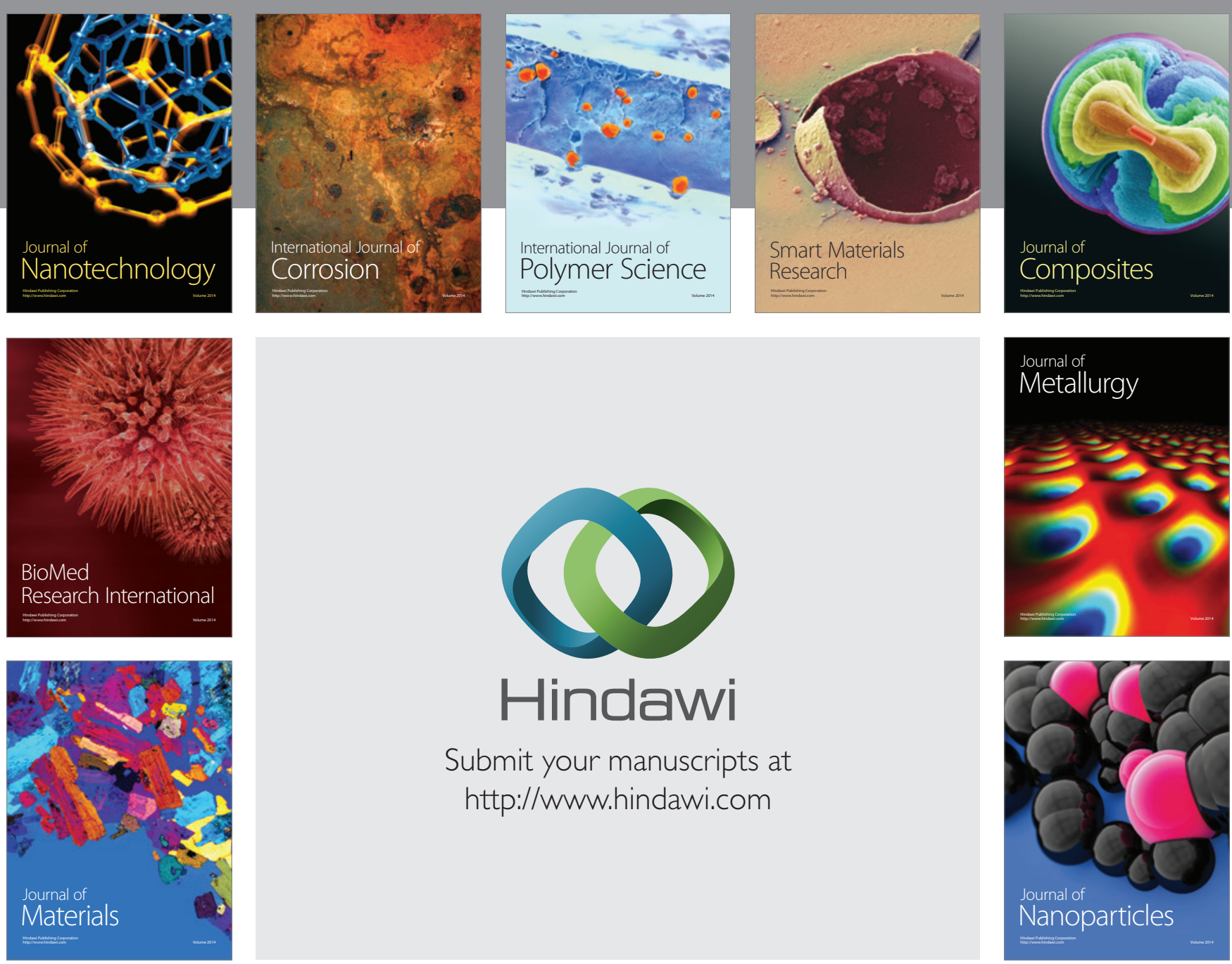

Submit your manuscripts at http://www.hindawi.com
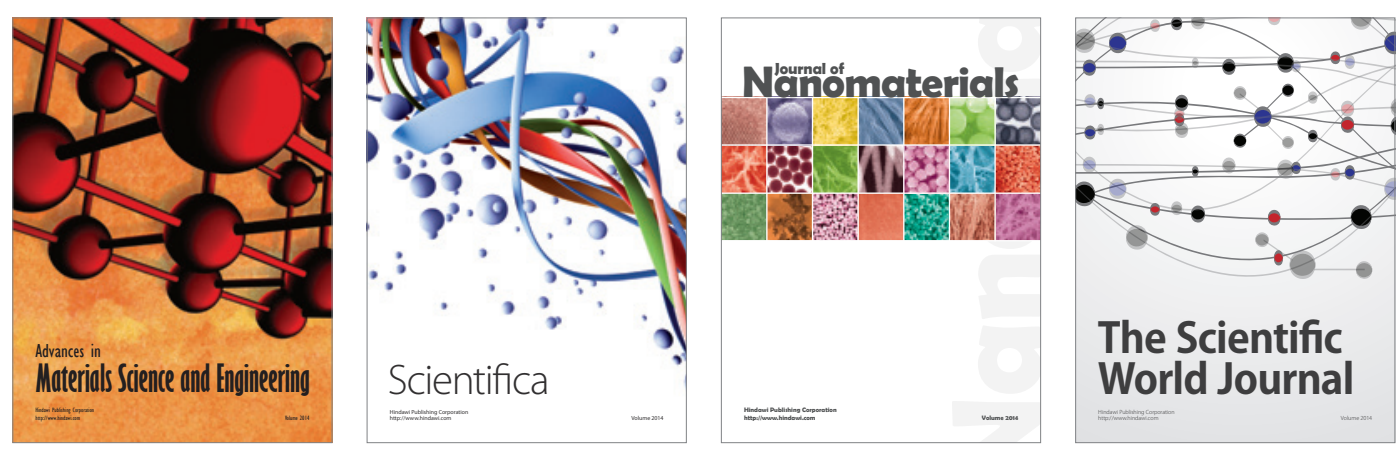

\section{The Scientific World Journal}
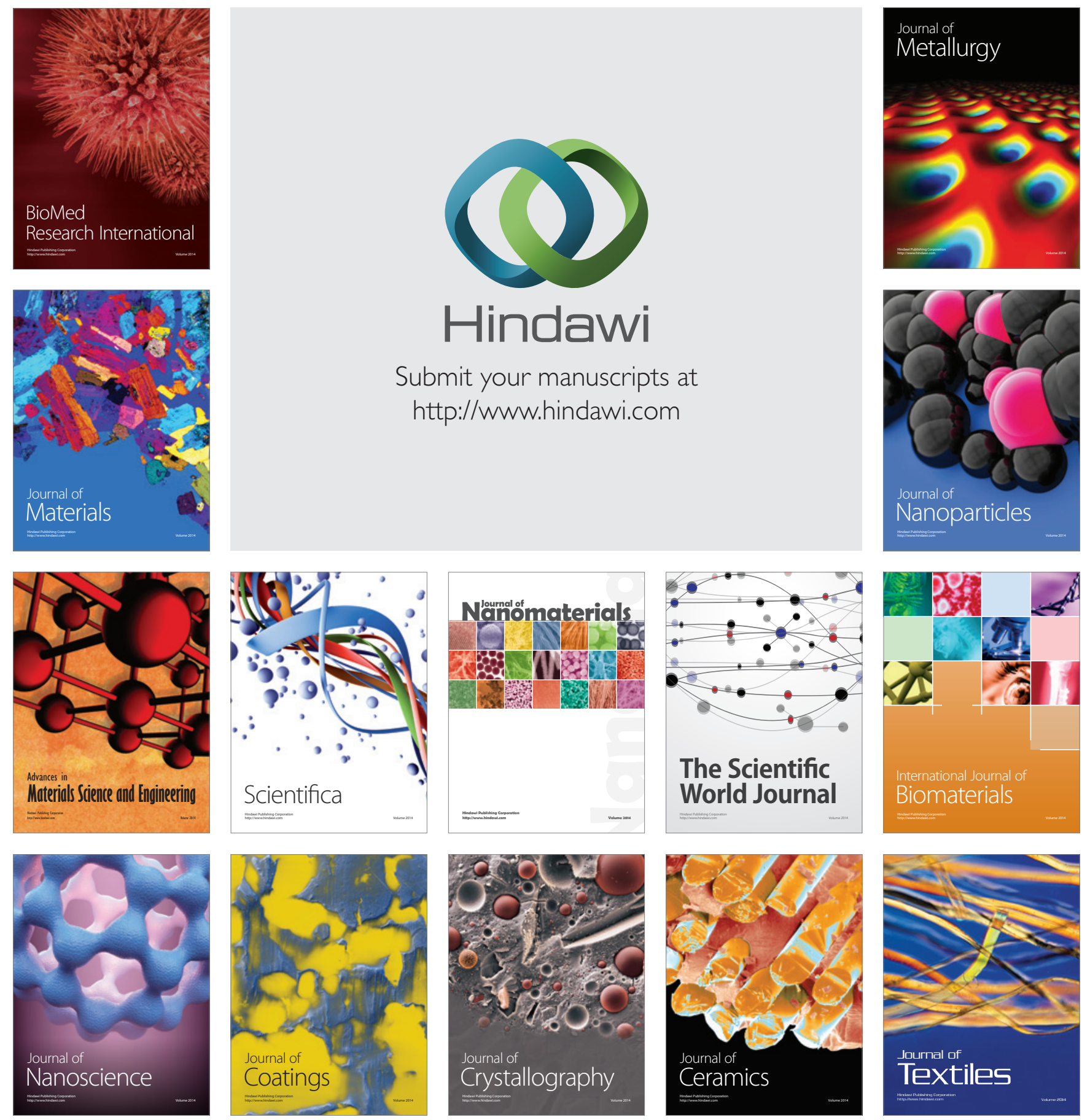